\title{
Synthesis of 28-membered macrocyclic polyammonium cations functionalized gold nanoparticles and their potential for sensing nucleotides
}

\author{
Tarun Kumar Misra, Chuen-Ying Liu* \\ Department of Chemistry, National Taiwan University, Taipei 10617, Taiwan
}

\section{A R T I C L E I N F O}

\section{Article history:}

Received 22 April 2008

Accepted 30 June 2008

Available online 3 July 2008

\section{Keywords:}

Gold nanoparticles

Macrocyclic polyammonium chloride

Water dispersion

Nucleotides

\begin{abstract}
A B S T R A C T
A new synthesis of underivatized gold nanoparticles (Au-NPs) in water stabilized by the highly water soluble 28-membered macrocyclic polyammonium chloride, [28]ane- $\left(\mathrm{NH}_{2}^{+}\right)_{6} \mathrm{O}_{2} \cdot 6 \mathrm{Cl}^{-}(28-\mathrm{MCPAC})$ is reported. In addition to providing stability, 28-MCPAC with its cationic form functionalizes the Au-NPs for sensing anions in water. The 28-MCPAC-Au-NPs show a surface plasmon band in the visible region ( $>520 \mathrm{~nm}$ ). By tuning the 28-MCPAC: $\mathrm{HAuCl}_{4}$ ratio, Au-NPs with different core diameters ranging from $4 \mathrm{~nm}$ to $6 \mathrm{~nm}$, as determined by TEM analysis, can be obtained. Particles are spherical, discrete, and appeared to have narrow size distributions. Raman spectroscopy confirms that the physisorption is responsible for the interaction between Au-NP surface and 28-MCPAC. The potential of the as-synthesized particles for sensing monophosphorylated nucleosides (nucleotides): 5-adenosine monophosphate (5-AMP), 5-cytosine monophosphate (5-CMP), 5-guanine monophosphate (5-GMP), and 5-uridine monophosphate (5-UMP) is investigated spectroscopically. Nucleotides-assisted agglomerations of 28-MCPAC-Au-NPs follow the order: 5-UMP > 5-GMP > 5-CMP > 5-AMP. An attempt is taken to prepare Au-NPs in water at pH 4.55 without an added stabilizer. Particles without an added stabilizer are short lived, and the TEM image shows that the particles aggregate following a quasi-two-dimensional self-assembly array.
\end{abstract}

(C) 2008 Elsevier Inc. All rights reserved.

\section{Introduction}

Metal nanoparticles exhibit unique electronic, optical, thermal, and catalytic properties that result from size, shape, and size distribution effects. They are promising as advanced materials due to their potential applications in the fields of physics, chemistry, biology, medicine, materials science, and many interdisciplinary fields $[1,2]$. Of the metal nanoparticles, Au-NPs are the most stable one and are extensively used in material science, catalysis, and biomedicine. Au-NPs act as versatile agents with a variety of biomedical applications including use in highly sensitive diagnostic assays [3], thermal ablation, radiotherapy enhancement [4,5], and for drug and gene delivery [6]. A catalytic function of Au-NPs for the oxidation of $\mathrm{NADH}$ to $\mathrm{NAD}^{+}$has also been investigated [7]. In addition, the surface plasmon resonance of Au-NPs makes them desirable agents as bio-sensors to detect biomolecules such as DNA, antigen-antibody complexes, and some proteins [8-11], and as optical sensors to detect anions, cations, and heavy metals [12-15].

The nanoparticles are in general unstable due to their high surface energy and need to be stabilized against agglomeration by

\footnotetext{
* Corresponding author. Fax: +886223638543.

E-mail address: cyliu@ntu.edu.tw (C.-Y. Liu)
}

using suitable stabilizer. Insofar as the synthesis of Au-NPs in a nonaqueous organic environment is concerned, attempts have been made to stabilize them by capping mostly with alkanethiols [16], $\omega$-functionalized alkanethiols [17], and aromatic thiols [18]. The stability is conferred by the chemisorption of thiol ligands onto the surface of Au-NPs through the formation of strong Au-S bonding [19]. These materials are so stable that even chemical reactions of the pendant functional group(s) if the employed thiol has any reactive functionality, are possible through usual techniques of organic synthesis $[20,21]$. Thus, these thiol-derivatized Au-NPs can be manipulated as simple 'organic compounds' or 'nanocompounds.' At the same time, another class of Au-NPs in nonaqueous solvents which can be regarded as underivatized Au-NPs (i.e. naked Au-NPs) was prepared following the two-phase method as described by Brust et al. [16], but without the addition of thiol [22, 23]. The stabilization of such nanoparticles is due to the presence of the quaternary ammonium bromide salt $\left(\mathrm{R}_{4} \mathrm{~N}^{+} \mathrm{Br}^{-}\right)$used as the phase transfer reagent $[22,23]$ which is physically adsorbed onto the particles through the formation of surface ion-pairs, with the bromide ion attached to the Au surface. The preparation of such nanoparticles is extremely important because the stabilization of the particles in solution does not involve the formation of strong metal-ligand bonds as in the case of alkanethiols, but rather results from electrostatic and dispersion interactions involving the chains of the quaternary ammonium cation in the organic solvent. 


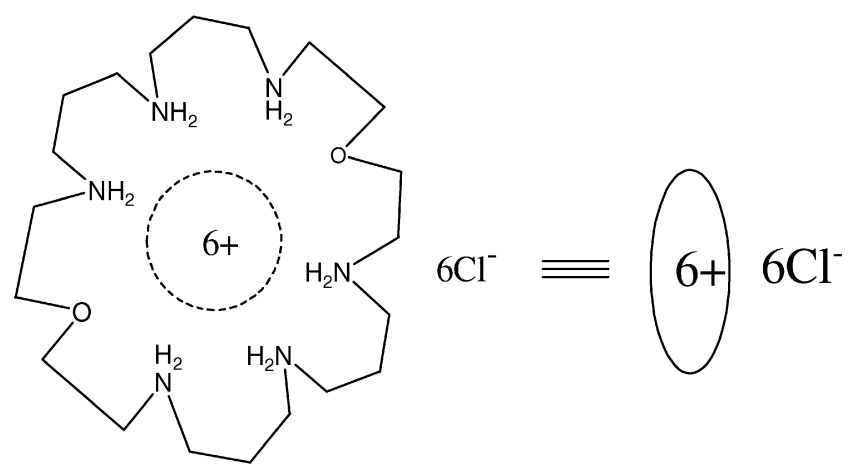

Scheme 1. [28]ane- $\left(\mathrm{NH}_{2}^{+}\right)_{6} \mathrm{O}_{2} \cdot 6 \mathrm{Cl}^{-}$.

Nevertheless, the biological applications of these materials are restricted since they are not dispersible in water, because their anionic particle surface is surrounded by long hydrophobic chains of the quaternary ammonium ions. Development of synthesis protocols for having water dispersible Au-NPs has been paid less attention and would have immediate applications in catalysis, sensors, molecular markers, and in particular, biological applications such as biolabeling and drug delivery. Realizing the importance of water soluble Au-NPs, researchers have therefore, used a number of different stabilizers containing at least two functional groups including a thiol group such as tiopronin [24], 4-hydroxythiophenol [25], mercaptosuccinic acid [26], and quaternaryammonium-thiol [27] for nanoparticles stabilization in aqueous solution. The stabilization of nanoparticles is attributed to the fact that the thiol end of these surfactants chemically adsorbed onto the gold surface by making $\mathrm{Au}-\mathrm{S}$ bond and other end containing non-thiol group(s) provides an electrophilic environment that helps them to disperse in water. These materials can also be regarded as thiol-derivatized 'organic compounds' or 'nanocompounds' soluble in water and like thiol-derivatized nanoparticle they show similar chemical functionalization [28]. In contrast, the synthesis of underivatized nanoparticles in water is rare and mainly based on citrate reduction methods $[29,30]$ where citrate functions as a reducing agent and an electrostatic capping ligand. Stabilization arises from electrostatic repulsion between neighboring Au-NPs due to the negative surface charge created by the citrate layer.

The present work is reported a new synthesis of underivatized Au-NPs stabilized by a macrocyclic polyammonium chloride. For a comparative study, the preparation of Au-NPs in water without an added stabilizer is also described. Macrocyclic polyammonium chloride is a cyclic protonated secondary aliphatic polyamine with chloride anions as counter ions. It is highly water soluble and well known as anion receptor because of the high cationic charge on its protonated form. Protonation introduces rigidity into the receptor because positive charges on adjacent nitrogens tend to adopt anticonformations to minimize electrostatic repulsion, resulting in a more circular shape [31]. However, no attempt has yet been made to explore their potential for the stabilization of nanoparticles. In the present investigation, we select a 28 -membered macrocyclic polyammonium chloride, [28]ane- $\left(\mathrm{NH}_{2}^{+}\right)_{6} \mathrm{O}_{2} \cdot 6 \mathrm{Cl}^{-}$(28-MCPAC) for the stabilization of the Au-NPs. The chemical structure of the 28-MCPAC is depicted in Scheme 1. Synthesis and anion recognition properties of this ligand are well-documented [32-36]. The chemical structure of 28-MCPAC, exhibits six protonated secondary aliphatic amines in a cyclic form with equal number of chloride anions as counter ions. The structure of the 28-MCPAC reveals that it can be regarded as an efficient stabilizer for synthesizing underivatized nanoparticles as it has no free coordination site to coordinate. A consequence of using 28-MCPAC as stabilizer is that it would functionalize the Au-NPs with its cationic form, for sensing anions in water. Thus, their potential for sensing nucleotides is investigated spectroscopically and is also reported herein. Nucleotides are of prime importance for many biological processes and considerable efforts have therefore been made to build artificial receptors or sensors for this class of compounds [37]. Potential use of Au-NPs as sensors are usually based on detecting the shift in surface plasmon peak, due to either change in the dielectric constant around the nanoparticles as a result of adsorption of analyte molecules, or due to analyte-induced agglomeration of the nanoparticles. Both these effects rely on the selectivity provided by the functionalized capping agents, highlighting the significance of the chemical methods of synthesis and stabilization of nanoparticles for use as solution based sensors.

\section{Materials and methods}

\subsection{Materials}

Hydrogen tetrachloroaurate(III) tetrahydrate (BDH, England), sodium borohydride (Acros, Belgium), 5-AMP, 5-CMP, 5-GMP, and 5-UMP (Sigma, St. Louis, MO, USA) were purchased from the indicated sources and were used as received without further purification. Purified water $(18 \mathrm{M} \Omega \mathrm{cm}$ ) from a Milli-Q water purification system (Millipore, Bedford, MA, USA) was used to prepare all solutions. 28-MCPAC was prepared following the reported method [32]

\subsection{Methods}

\subsubsection{Synthesis of 28-MCPAC-capped Au-NPS}

Three sets of aqueous dispersion of Au-NPs were synthesized by the reduction of tetrachloroauric acid $\left(\mathrm{HAuCl}_{4}\right)$ with sodium borohydride $\left(\mathrm{NaBH}_{4}\right)$ in the presence of 28-MCPAC. Typically, to an aqueous solution of 28-MCPAC ( $10 \mathrm{~mL}, 1 \mathrm{mM}$ stock solution) an aliquot of the aqueous solution of $\mathrm{HAuCl}_{4}(0.25-1.00 \mathrm{~mL}, 5 \mathrm{mM}$ stock solution) was added with stirring at room temperature. The color of the solution became yellowish and then vanished within a few seconds. Freshly prepared $\mathrm{NaBH}_{4}$ stock solution $(0.50-2.00 \mathrm{~mL}$, $10 \mathrm{mM}$ ) was then completely added within a few seconds and stirred an additional $20 \mathrm{~min}$. The color of these solutions immediately became red (like wine) and gradually changed to pink-red, indicating the formation of Au-NPs. The solutions were aged $2 \mathrm{~h}$ at room temperature and stored in the refrigerator for further studies. The molar ratio of $\mathrm{NaBH}_{4}$ to $\mathrm{HAuCl}_{4}$ was kept at $4: 1$ while that of 28 -MCPAC to $\mathrm{HAuCl}_{4}$ was varied as $8: 1,4: 1$ and $2: 1$. The assynthesized Au-NP solutions were assigned with respect to the volume of added $\mathrm{HAuCl}_{4}: \mathrm{S} 1\left(\mathrm{HAuCl}_{4}: 0.25 \mathrm{~mL}\right), \mathrm{S} 2\left(\mathrm{HAuCl}_{4}: 0.50 \mathrm{~mL}\right)$ and $\mathrm{S} 3\left(\mathrm{HAuCl}_{4}: 1.00 \mathrm{~mL}\right)$.

\subsubsection{Preparation of Au-NPs in water ( $\mathrm{pH}$ 4.55)}

For the preparation of aqueous Au-NPs without 28-MCPAC, the $\mathrm{pH}$ of water was adjusted to 4.55 with hydrochloric acid. The $\mathrm{HAuCl}_{4}(0.50 \mathrm{~mL}, 5 \mathrm{mM})$ was added into the aqueous solution (10 mL, pH 4.55) with stirring at room temperature. Freshly prepared $\mathrm{NaBH}_{4}(1 \mathrm{~mL}, 10 \mathrm{mM})$ was then added within a few seconds and stirred continuously for $5 \mathrm{~min}$. The generation of a red-wine colored solution was observed immediately. The solution was divided into two parts. One part was stored in the refrigerator and the other was used to record the UV-vis spectra at intervals over $3 \mathrm{~h}$ at room temperature.

\subsubsection{Preparation of 28-MCPAC-capped Au-NPs/nucleotide solutions}

Solutions of 5-AMP, 5-CMP, 5-GMP, and 5-UMP (2 mM stock solution) were prepared in water. The as-synthesized Au-NPs solution (S2) was diluted two times. With $4 \mathrm{~mL}$ of diluted Au-NPs solution, $1 \mathrm{~mL}$ of nucleotide was mixed and shaken $30 \mathrm{~s}$ and monitored spectroscopically. 


\subsubsection{Measurements}

UV-vis absorption spectra were recorded on a Hitachi U-2800A spectrophotometer using quartz cell with a path length of $1 \mathrm{~cm}$. $\mathrm{pH}$ of all the solutions was measured using a PHM210 standard pH meter (Radiometer, Copenhagen). Solution-phase Raman spectra were recorded using a Nicolet Almega-XR Micro-Raman Spectrometer equipped with CCD detector and a $780 \mathrm{~nm}$ diode laser. The Raman spectrum was collected within $2900-3500 \mathrm{~cm}^{-1}$ interval with $4 \mathrm{~cm}^{-1}$ resolution using $100 \mathrm{~mW}$ of excitation laser power. TEM photographs were taken on Hitachi H-7100 transmission electron microscopes at an acceleration voltage of $75 \mathrm{kV}$. The samples for TEM measurements were prepared by placing a drop of aqueous solutions of gold nanoparticles onto a copper micro grid and dried at room temperature. The average particle sizes and size distributions were obtained on the basis of the measurements of 100-180 particles. The average diameter $D$ and the standard deviation $\sigma$ of the size distribution are calculated from Eqs. (1) and (2) as follows:

$D=\frac{\sum n_{i} d_{i}}{N}$

$\sigma=\sqrt{\frac{\sum n_{i}\left(d_{i}-D\right)^{2}}{N-1}}$,

where $d_{i}$ is the diameter of particles, $n_{i}$ is the number of particles having diameter $d_{i}$, and $N$ is the total number of particles counted.

\section{Results and discussion}

\subsection{Characterization of the synthetic process}

An aqueous solution of 28-MCPAC ( $1 \mathrm{mM}$ ) exhibits $\mathrm{pH}$ of 4.55 . The 28-MCPAC-stabilized Au-NPs were prepared by mixing an aqueous solution of the 28-MCPAC with an aqueous solution of $\mathrm{HAuCl}_{4}$ followed by $\mathrm{NaBH}_{4}$ reduction. Upon addition of $\mathrm{HAuCl}_{4}$ into the 28-MCPAC solution, the yellow color of $\mathrm{HAuCl}_{4}$ disappeared within a few seconds, indicating some sort of interaction between the macrocyclic polyammonium ion and $\mathrm{AuCl}_{4}^{-}$and can be regarded as the formation of super-complex ([28]ane- $\left(\mathrm{NH}_{2}^{+}\right)_{6} \mathrm{O}_{2}$ $\left(\mathrm{AuCl}_{4}^{-}\right)$). The UV-vis spectra of 28-MCPAC (a), $\mathrm{HAuCl}_{4}$ (b and insert'), the mixture of 28-MCPAC and $\mathrm{HAuCl}_{4}$ (molar ratio, 4:1; c), and 28-MCPAC-stabilized Au-NPs solution (d) were recorded and are shown in Fig. 1. In water, 28-MCPAC (1 mM) shows virtually no absorption peak in the visible region. An aqueous solution with a high concentration of $\mathrm{HAuCl}_{4}(0.25 \mathrm{mM})$ shows an absorption peak at $290 \mathrm{~nm}$ (Fig. 1b) and in a more dilute solution, the $\mathrm{HAuCl}_{4}(0.01 \mathrm{mM})$ shows another strong peak at $217 \mathrm{~nm}$ (Fig. 1, insert). These characteristic resonances correspond to the ligand to metal charge transfer (LMCT) transition of the $\mathrm{AuCl}_{4}^{-}$ions [38]. The peak at $290 \mathrm{~nm}$ disappeared in the presence of 28-MCPAC (Fig. 1c) due to the formation of the super-complex. Moreover, these solutions showed no absorbance over $400 \mathrm{~nm}$. The mixed solution (28-MCPAC $\left.+\mathrm{HAuCl}_{4}\right)$, after $\mathrm{NaBH}_{4}$ reduction, produced a pinkred colored solution with an absorption peak at $527 \mathrm{~nm}$ and no observable peak below $400 \mathrm{~nm}$, indicating that $\mathrm{AuCl}_{4}^{-}$has completely been reduced to form Au-NPs.

The molar ratios of 28-MCPAC to the $\mathrm{HAuCl}_{4}$, gold salt were varied to $8: 1(\mathrm{~S} 1), 4: 1(\mathrm{~S} 2)$ and $2: 1$ (S3) to optimize the reaction conditions. Upon addition of gold salt to the solution of 28-MCPAC, a super-complex was formed accompanied by the release of protons as shown in reaction 3. Consequently the $\mathrm{pH}$ of the solutions decreased to 2.97 for S1, 2.83 for S2, and 2.74 for S3. However, with the addition of $\mathrm{NaBH}_{4}$, the final $\mathrm{pH}$

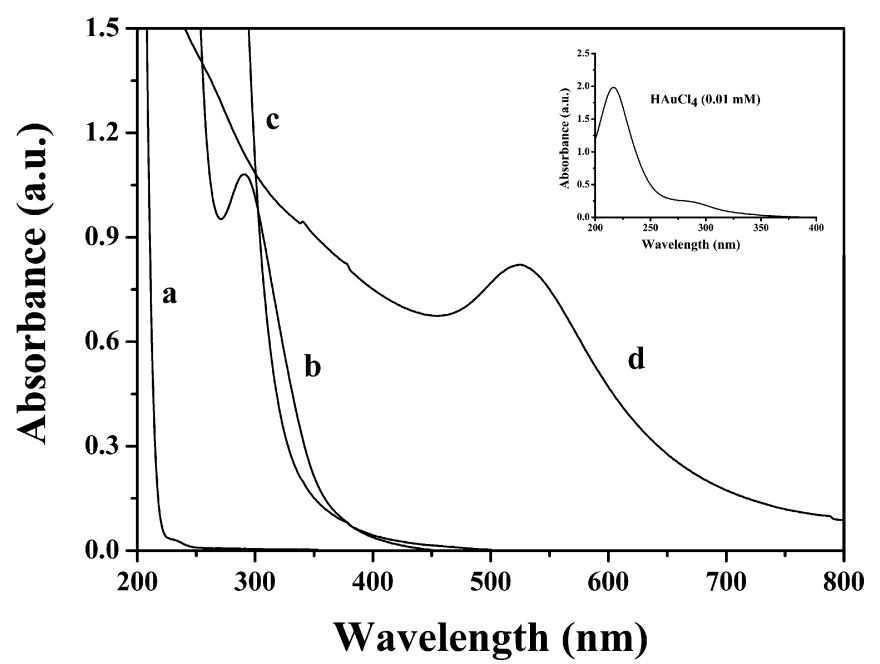

Fig. 1. UV-vis spectra of (a) 28-MCPAC (1 mM); (b) $\mathrm{HAuCl}_{4}(0.25 \mathrm{mM})$; (c) the mixture of 28-MCPAC and $\mathrm{HAuCl}_{4}$ (molar ratio, 4:1); (d) the mixture ' $c$ ' after treated with $\mathrm{NaBH}_{4}$; and the insert: $\mathrm{HAuCl}_{4}(0.01 \mathrm{mM})$.

$$
\begin{aligned}
& \text { [28]ane- }\left(\mathrm{NH}_{2}^{+}\right)_{6} \mathrm{O}_{2}+n \mathrm{HAuCl}_{4} \\
& \qquad[28] \text { ane- }\left(\mathrm{NH}_{2}^{+}\right)_{6} \mathrm{O}_{2} \cdot n \mathrm{AuCl}_{4}^{-}+n \mathrm{H}^{+}, \\
& n \mathrm{Au}^{0}+[28] \text { ane- }\left(\mathrm{NH}_{2}^{+}\right)_{6} \mathrm{O}_{2}+n \mathrm{Cl}^{-} \longleftarrow \mathrm{NaBH}_{4} \\
& \mathrm{NaBH}_{4}+4 \mathrm{H}_{2} \mathrm{O} \longrightarrow \mathrm{H}_{3} \mathrm{BO}_{3}+\mathrm{NaOH}+\mathrm{H}_{2},
\end{aligned}
$$

of the reaction mixtures (S1: 3.47, S2: 3.25, and S3: 3.18 ) increased, due to the strong hydrolysis of $\mathrm{NaBH}_{4}$ (reaction 5). It is therefore clear that the final $\mathrm{pH}$ is determined by the combination of reactions 3 and 5 .

\subsection{UV-vis spectroscopy studies}

The UV-vis spectra of 28-MCPAC-stabilized Au-NPs are shown in Fig. 2. The UV-vis spectra of Au-NP samples S1, S2, and S3 show absorption bands of $525 \mathrm{~nm}$ (Fig. 2a), $527 \mathrm{~nm}$ (Fig. 2b), and $526 \mathrm{~nm}$ (Fig. 2c), respectively. The band of each sample results from the surface plasmon resonance of the Au-NPs. The surface plasmon resonance band of well dispersed Au-NPs is calculated theoretically to be at $510-525 \mathrm{~nm}$ in an aqueous system [39]. It is evident that for spherical metal nanoparticles of size $3-20 \mathrm{~nm}$, the absorption spectrum does not strongly depend on particle size [39]. This is because for particle sizes below ca. $20 \mathrm{~nm}$ in diameter, the quadruple and higher-order terms in the Mie summation become significant [40]. The source of surface plasmon resonance in this region is due to the transverse oscillation of the surface electrons. It has been reported that the red-shifting and broadening of the transverse band along with the appearance of a longwavelength band, termed as the longitudinal band which is originated from the longitudinal oscillation of electrons, is observed when individual particles are aligned into a definite array or agglomerate $[41,42]$. Since as-synthesized Au-NPs in water showed no red-shifted transverse band and or no longitudinal band, the samples S1-S3 are therefore appeared to be well dispersed aqueous Au-NPs.

The wavelength maxima did not significantly change as the molar ratio was varied for S1-S3. However, the intensity of the absorbance significantly increased $(\mathrm{S} 1<\mathrm{S} 2<\mathrm{S} 3$, Fig. 2) with the decrease of molar ratio. The decrease of molar ratio caused the increase of the added volume of $\mathrm{HAuCl}_{4}$ in the solutions, S1-S3. Therefore, it is obvious that the intensity of the absorption band increased with the increasing $\mathrm{HAuCl}_{4}$ concentration, reflecting the formation of more particles. We also examined the effect of the 


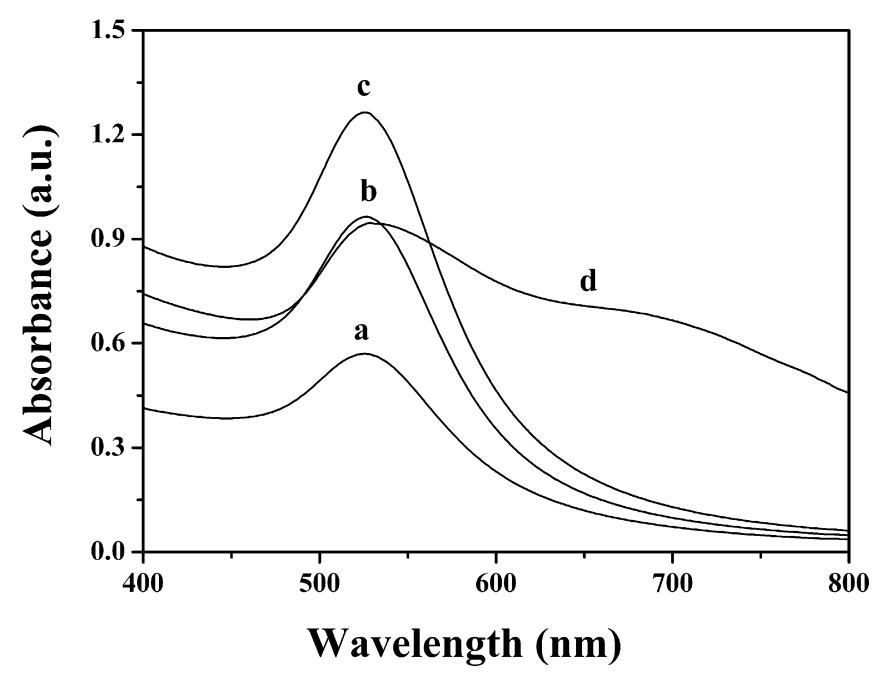

Fig. 2. UV-vis spectra of 28-MCPAC-Au-NPs solutions after $2 \mathrm{~h}$ of preparation; the 28-MCPA:HAuCl 4 molar ratios: (a) 8:1 (S1); (b) 4:1 (S2); (c) 2:1 (S3); and (d) AuNPs without 28-MCPAC at pH 4.55 (S4) (after $1 \mathrm{~h}$ ).

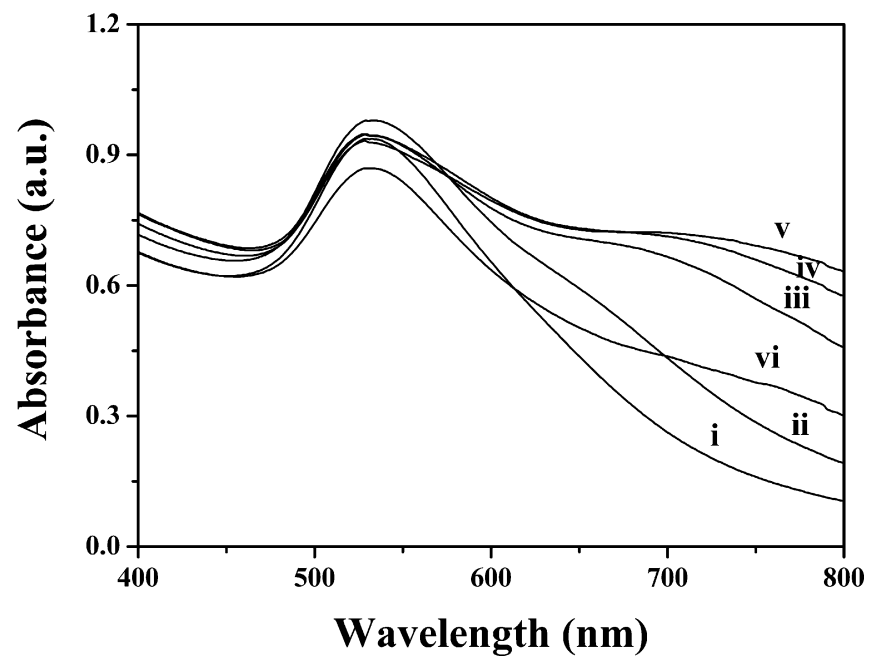

Fig. 3. UV-vis spectra of Au-NPs without 28-MCPAC (pH 4.55) (S4) over different time intervals: (i) $5 \mathrm{~min}$; (ii) $30 \mathrm{~min}$; (iii) $1 \mathrm{~h}$; (iv) $2 \mathrm{~h}$; (v) $3 \mathrm{~h}$; at room temperature and (vi) the same stored in refrigerator after $2 \mathrm{~h}$.

molar ratio of $\mathrm{HAuCl}_{4}: \mathrm{NaBH}_{4}$. Solutions with molar ratios of $1: 3$ and 1:5 $\mathrm{HAuCl}_{4}: \mathrm{NaBH}_{4}$ coagulated within a few hours (data not shown), while a ratio of 1:4 produced a stable nanoparticles solution. The later ratio was therefore selected for all studies.

\subsection{Role of the 28-MCPAC, bare Au-NPs and stability}

To investigate the role of the 28-MCPAC, or rather 28-macrocyclic polyammonium cations $\left(28-\mathrm{MCPA}^{6+}\right.$ ) for the stabilization of Au-NPs in water, the Au-NPs (S4) in an aqueous solution of $\mathrm{pH} 4.55$ (the $\mathrm{pH}$ was chosen because $1 \mathrm{mM}$ aqueous solution of 28-MCPAC has the $\mathrm{pH} 4.55$ ) without 28-MCPAC was prepared and the corresponding UV-vis spectrum recorded after $2 \mathrm{~h}$ of aging is shown in Fig. 2d. Unlike 28-MCPAC-stabilized Au-NPs, the UV-vis spectrum of $\mathrm{S} 4$ shows a broad peak centered at $533 \mathrm{~nm}$ along with a very broad band at a long-wavelength (>690 nm) (Fig. 2d). Thus, the UV-vis spectrum of S4 suggests that the Au-NPs in water without 28-MCPAC are self-assembled or are in aggregated forms. The process of agglomeration or self-assembly was observed by recording the UV-vis spectra over different time intervals as shown in Fig. 3. The UV-vis spectrum recorded after $5 \mathrm{~min}$ of reaction showed a red-shifted transverse band at $533 \mathrm{~nm}$ (Fig. 3i). The broadening

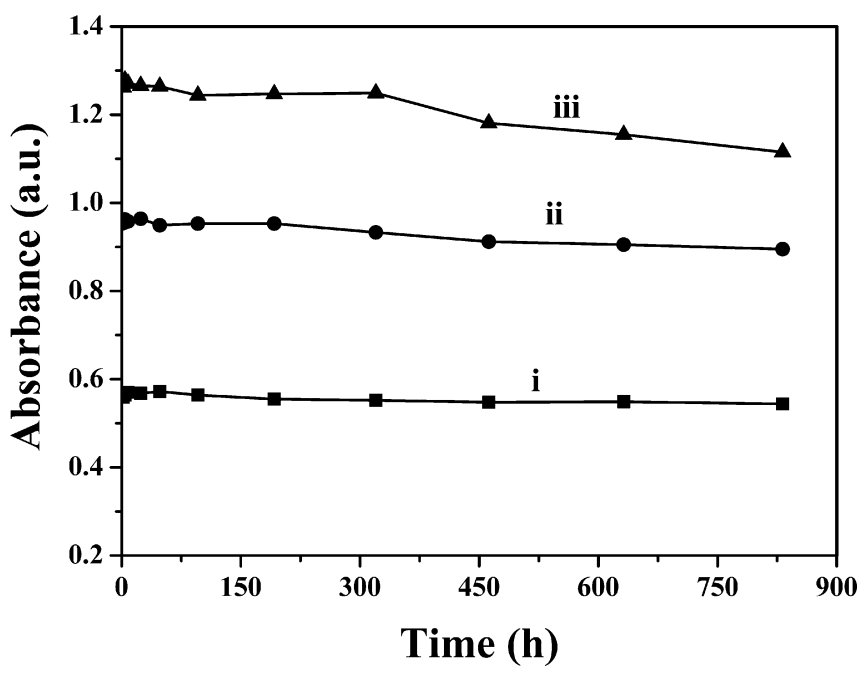

Fig. 4. Plot of absorbance vs time. The 28-MCPAC: $\mathrm{HAuCl}_{4}$ molar ratios: (a) 8:1 (S1) (b) $4: 1$ (S2); (c) 2:1 (S3).

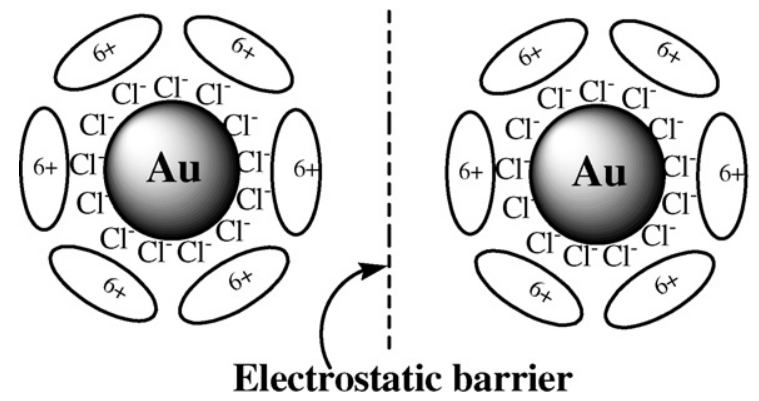

Scheme 2. Au-NPs stabilized by 28-MCPAC.

of the transverse band along with an appearance and broadening of the longitudinal band (>690 nm) was observed over time (Figs. 3ii-3v). The intensity of the longitudinal band also increased with time. The initial red-wine color of the solution turned blue and then became colorless after $4-5 \mathrm{~h}$. Thus, the result indicates that the as-prepared Au-NPs without 28-MCPAC were subsequently self-assembled and agglomerated. Fig. 3vi was recorded after $2 \mathrm{~h}$ of storage of S4 in the refrigerator. A comparison of a spectrum of Fig. 3iv with Fig. 3vi, reveals that the process of agglomeration and self-assembly could be slowed by storing the NPs solution in the refrigerator. In contrast, the Au-NPs prepared in the presence of 28-MCPAC do not show an absorption band corresponding to the longitudinal oscillation, indicating the presence of well dispersed, individual particles. Therefore, the role of the 28-MCPAC is clear as it can prevent the Au-NPs from agglomeration. From the experimental point of view it is noteworthy that the chloride ions present in $\mathrm{S} 4$ sourced from $\mathrm{HCl}$ (used to adjust $\mathrm{pH}$ ) and the precursor salt, $\mathrm{HAuCl}_{4}$ (reaction 4), could not stabilize the Au-NPs (S4) entirely from agglomeration. It is therefore indicated that 28-macrocyclic polyammonium cations play important role along with chloride ions (counter anions) in stabilizing Au-NPs (S1-S3) from agglomeration. A possible explanation is that the macrocycle molecules adsorbed on the Au-NPs might form ion-pairs with $\mathrm{Cl}^{-}$ions attached to the Au surfaces, and the cationic macrocycle surrounded the $\mathrm{Cl}^{-}$ions layer by electrostatic interactions as shown in Scheme 2. In fact, anion-induced cation adsorption on metal nanoparticles surface through the formation of surface ion-pairs has been described in some reports [22,23, 43,44]. For instances, Schiffrin et al. [22] and Wang et al. [23] demonstrated the stabilization of Au-NPs through the formation of $\mathrm{TOA}^{+}-\mathrm{Br}^{-}$and $\mathrm{CTA}^{+}-\mathrm{Br}^{-}$surface ion-pairs in organic solutions, 


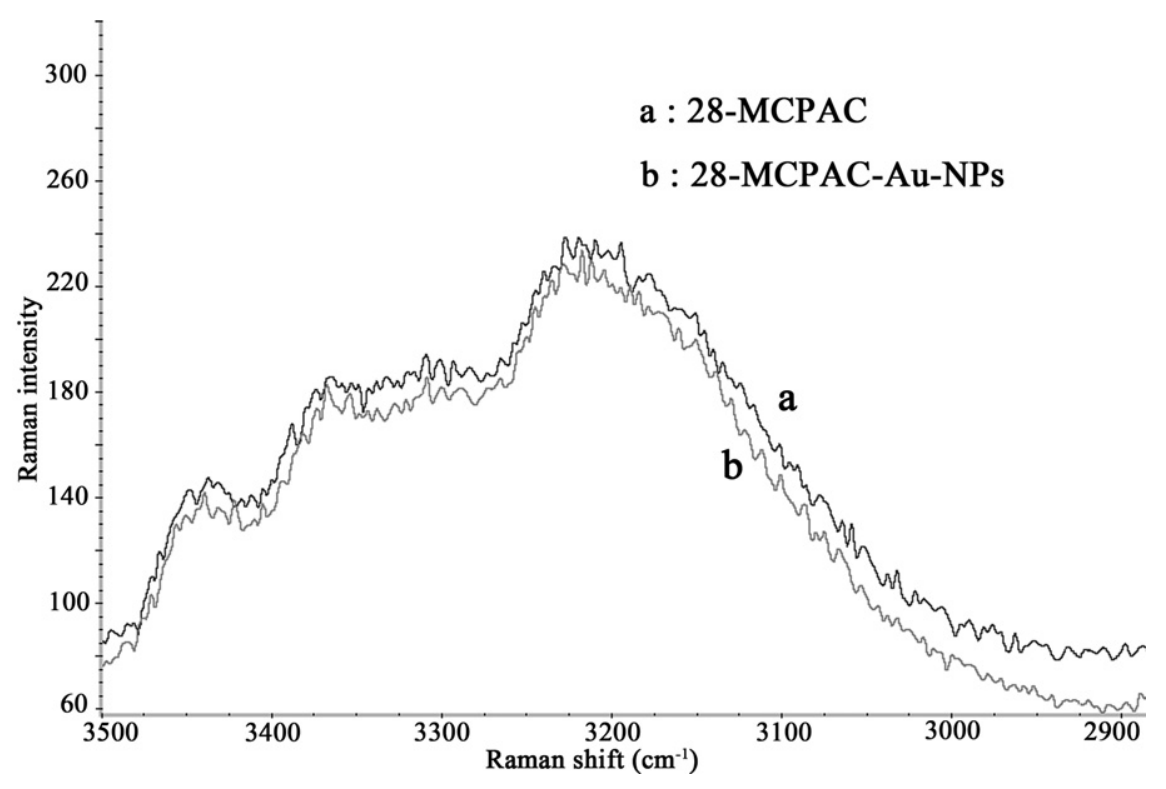

Fig. 5. Raman spectra of (a) pure 28-MCPAC and (b) 28-MCPAC-Au-NPs.

respectively; Kuo et al. [43] and Wang et al. [44] demonstrated the stabilization of Au-NPs through the formation of protonated polyethylenimie ${ }^{+}-\mathrm{Cl}^{-}$surface ion-pairs in aqueous solutions, separately. In this study, $28-\mathrm{MCPA}^{6+}-6 \mathrm{Cl}^{-}$may play a role similar to that of reported results. As a result, particles get surrounded by highly positive charge macrocyclic polyammonium ions and stabilization arises from electrostatic repulsion between neighboring Au-NPs due to the positive charge created by macrocyclic polyammonium layer. It also makes particles quite discrete. Moreover, the observed strong surface plasmon band (Fig. 2c) reveals that unlike chemically bound thiol-derivatized functional groups [24-27], the surface-bound 28-MCPAC molecules on the gold particle surface are physically associated and do not dampen strongly the surface electron resonance. The Au-NPs stabilized by the 28-MCPAC are extremely stable over time, as indicated by monitoring the peak absorbance. Changes of absorbance at surface plasmon band of all solutions (S1-S3) over a month were monitored and plotted against time as shown in Fig. 4. Fig. 4 reveals that there is no discernable decrease or minimal decrease of absorbance observed over a month. The result clarifies that the 28-MCPAC not only prevents the particles from agglomeration but also stabilizes them for a longer time.

\subsection{Raman spectroscopy}

Raman measurements were taken in an attempt to probe possible mode of adsorption (physisorption or chemisorption) of 28MCPAC onto the gold particle surface. Fig. 5 shows the Raman spectra of pure 28-MCPAC (a) and 28-MCPAC-Au-NPs (b) recorded over the frequency range $3500-2900 \mathrm{~cm}^{-1}$. The absorbance in this region can be attributed to the stretching frequency of $\mathrm{N}-\mathrm{H}$ and $\mathrm{C}-\mathrm{H}$ bonds. A broad $\mathrm{N}-\mathrm{H}$ stretch band superimposed upon $\mathrm{C}-\mathrm{H}$ stretch band makes an overall broad band. Both the spectra (Figs. 5a and 5b) are identical; no noticeable dampening was observed in the spectrum of 28-MCPAC-Au-NPs compared to that of 28-MCPAC. The result indicates that the 28-MCPAC adsorbed physically onto the surface of Au-NP and provided them adequate stability. This is consistent with the proposed mechanism that the 28-MCPAC adsorbed on the Au-NPs might form ion-pairs with $\mathrm{Cl}^{-}$ions attached to the Au surfaces, and the cationic macrocycle surrounded the $\mathrm{Cl}^{-}$ions layer by electrostatic interactions (Scheme 2).

\subsection{TEM measurements}

Fig. 6 displays the TEM images of the as-synthesized 28MCPAC-stabilized Au-NPs (S1 (a), S2 (b), and S3 (c)) deposited on the copper grid from the aqueous solutions. The corresponding histograms depicting the size distributions of the particles (S1 (a), S2 (b), and S3 (c)) were obtained directly from the enlarged TEM images of S1, S2, and S3 by counting 100, 178, and 134 particles, respectively. The average diameters $D$ (and standard deviations $\sigma$ ) of the samples S1, S2, and S3, are $4.4 \mathrm{~nm}$ (1.3), $5.7 \mathrm{~nm}$ (1.5), and $5.3 \mathrm{~nm}$ (1.5), respectively. Thus, by tuning the 28-MCPAC: $\mathrm{HAuCl}_{4}$ ratio, particles with core diameter of different sizes were obtained. In each sample, a narrow size distribution of particles was observed, as indicated by the calculated standard deviation of $\leqslant 1.5$. All particles were spherical and well-dispersed. The number of particles as well as some short range aggregation increased from $\mathrm{S} 1<\mathrm{S} 2<\mathrm{S} 3$ as the added amount of $\mathrm{HAuCl}_{4}$ and $\mathrm{NaBH}_{4}$ increased accordingly. The increase of particles is also responsible for increasing the UV-vis intensity (Fig. 2). The particles in S1 were hardly aggregated and well-dispersed. The short range aggregation in S3 was comparatively higher than S2. Notably, further decreases molar ratio of 28-MCPAC to $\mathrm{HAuCl}_{4}$ lead to the severe aggregation of Au-NPs as the solution became turbid within a few minutes of the addition of $\mathrm{NaBH}_{4}$. These observations in conjunction with the UV-vis spectroscopy data permitted us to conclude that the sample S2 (28-MCPAC: $\left.\mathrm{HAuCl}_{4}, 4: 1\right)$ is the optimum choice to obtain highly concentrated, well-dispersed particles with relatively low aggregation of particles.

Fig. 7 shows the TEM image of Au-NPs prepared from the aqueous solution at a $\mathrm{pH} 4.55$ without 28-MCPAC. After $2 \mathrm{~h}$ of preparation, the TEM image was taken. Particle sizes were greater than $15 \mathrm{~nm}$ and self-assembled into a quasi-two-dimensional array. It is probable that the particles were not uniformly coated with chloride ions sourced from $\mathrm{HCl}$ (used to adjust $\mathrm{pH}$ ) and the precursor salt, $\mathrm{HAuCl}_{4}$ (reaction 4). The result supports the UV-vis outcome. Metal nanoparticles ordered into one-, two-, and threedimensional assembled structures are of great interest because their collective properties are expected to differ from those of the isolated individual nanoparticles. The arrangement of Au-NPs into two-dimensional array in the solution phase is a fascinating target because of their unique optical and electronic properties that may result from the specific alignment of the Au-NPs. It could be used as nanowires or nanosensors [45]. 

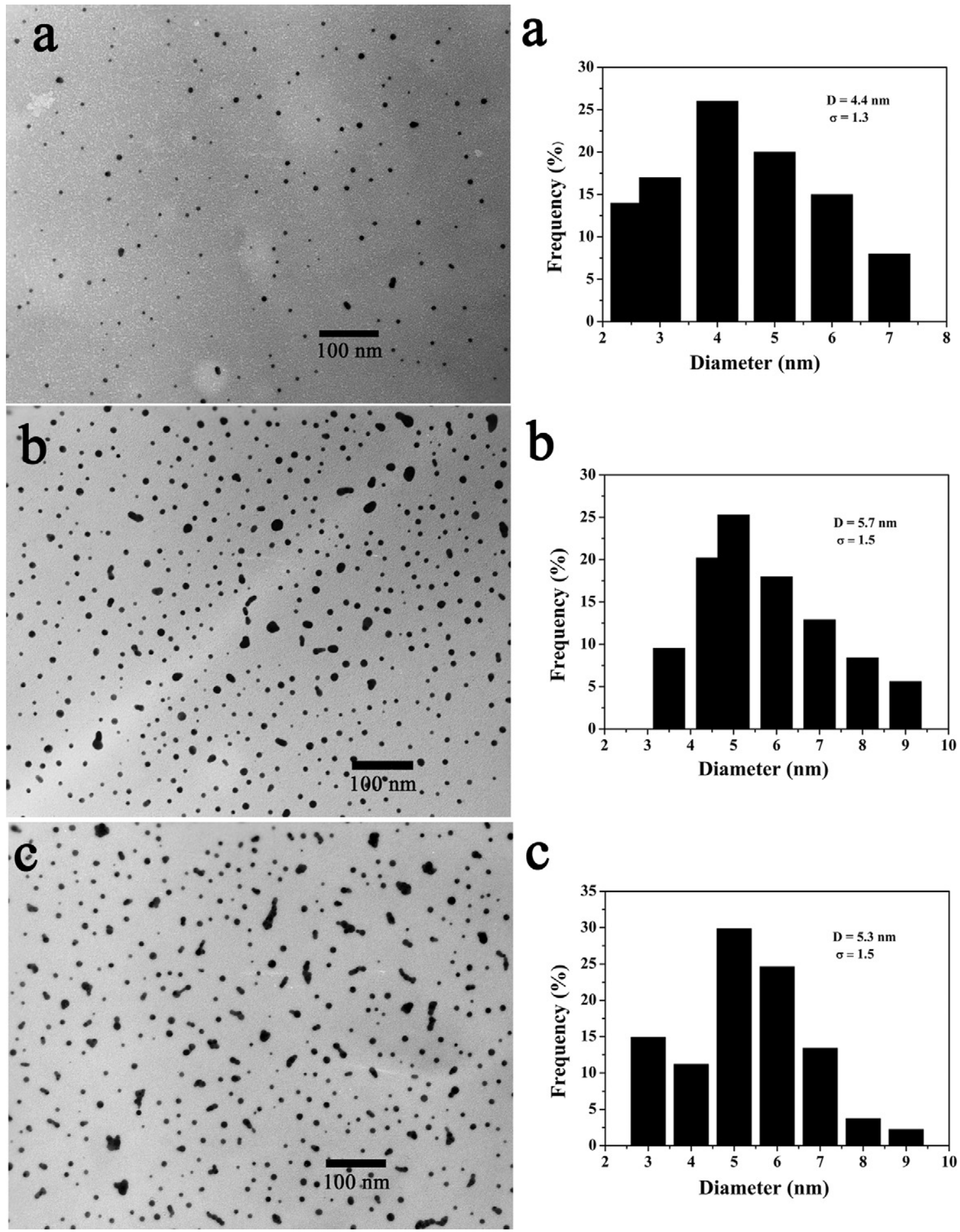

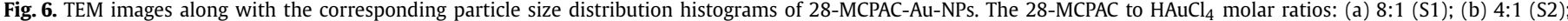
(c) 2:1 (S3). The percentages in the histograms were calculated based on the absolute particles numbers of 100,178 , and 134 for panels a, b, and c, respectively.

\subsection{Binding of Au-NPs by nucleotides}

As-synthesized Au-NPs are stabilized by 28-MCPAC which is a reputed anion receptor. To prove that as-synthesized Au-NPs are indeed functionalized with macrocyclic polyammonium cations for sensing anions, their potential for sensing nucleotides: 5-AMP, 5GMP, 5-CMP, and 5-UMP were investigated by UV-vis spectroscopy. The molecular structures of all of these nucleotides are depicted in Scheme 3. In a typical experiment, the solution S2 of Au-NPs was diluted two times and $4 \mathrm{~mL}$ of diluted Au-NPs was mixed with $1 \mathrm{~mL}$ of each nucleotide (2 $\mathrm{mM}$ stock solution) separately and the UV-vis spectra were recorded. The molar ratio of 28MCPAC to nucleotide was maintained at 1:1. The interactions of each nucleotide with Au-NPs were studied by monitoring changes at the surface plasmon band $(527 \mathrm{~nm})$ associated with nanoparticles aggregation. Fig. 8 shows the UV-vis spectra of 28-MCPACAuNPs/nucleotide solutions after standing for $5 \mathrm{~min}(\mathrm{~A}), 1 \mathrm{~h}$ (B), $2 \mathrm{~h}(\mathrm{C})$, and $4 \mathrm{~h}(\mathrm{D})$ at room temperature. The spectra b, c, d, and $\mathrm{e}$ in Fig. 8 are represented to the 28-MCPAC-Au-NPs in the presence of nucleotide 5-UMP, 5-AMP, 5-CMP, and 5-GMP, respec- 
<smiles>Nc1ncnc2c1ncn2[C@@H]1O[C@H](COP(=O)([O-])[O-])[C@@H](O)[C@H](O)[C@H]1O</smiles>

5-AMP

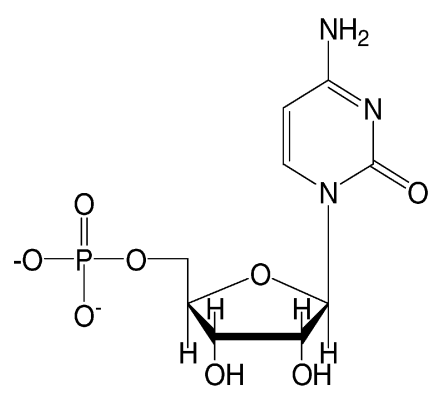

5-CMP<smiles>Nc1nc2c(ncn2C2OC(COP(=O)([O-])[O-])[C@@H](O)[C@H](O)[C@H]2O)c(=O)[nH]1</smiles>

5- GMP<smiles>O=c1ccn(C2(O)OC(COP(=O)([O-])[O-])[C@@H](O)[C@H](O)[C@H]2O)c(=O)[nH]1</smiles>

5-UMP

Scheme 3. Chemical structure of the nucleotides.

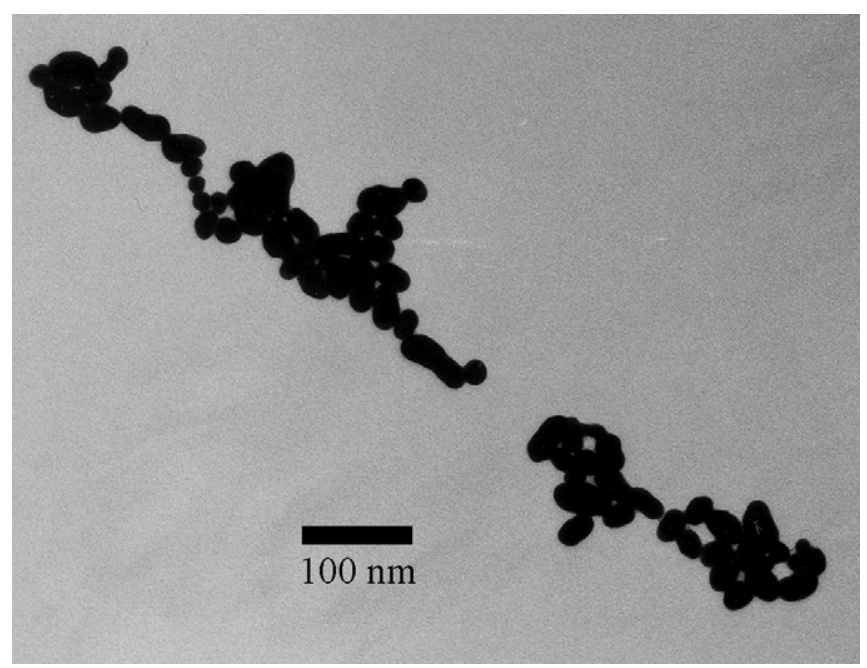

Fig. 7. TEM image of Au-NPs without 28-MCPAC (S4).

tively. For comparison, the spectrum of 28-MCPAC-Au-NPs (a) was also recorded. In contrast to the surface plasmon band $(527 \mathrm{~nm})$ of 28-MCPAC-Au-NPs solution (a), noticeable red-shifting, broadening, and increase of intensity were observed for 28-MCPAC-Au-NPs in the presence of 5-AMP (c, $549 \mathrm{~nm}), 5-\mathrm{CMP}$ (d, $551 \mathrm{~nm}$ ), and 5GMP (e, $553 \mathrm{~nm}$ ) after standing for 5 min (Fig. 8A). In contrast, intensity decreased and minimal red-shifting and broadening was observed in the presence of 5-UMP (b, $529 \mathrm{~nm}$ ) after standing for 5 min (Fig. 8A). The red-shifting and broadening of the surface plasmon band occurred significantly in case of 5-GMP (e, $596 \mathrm{~nm})$, 5-CMP (d, $576 \mathrm{~nm}$ ), and 5-UMP (b, $570 \mathrm{~nm}$ ) whereas the least effect was observed for 5-AMP (c, $556 \mathrm{~nm}$ ) after standing for $4 \mathrm{~h}$ (Fig. 8D). The red-shifting and broadening of the surface plasmon band of Au-NPs can be attributed to the agglomeration of Au-NPs.
Thus, the results indicate that the nucleotides led to agglomeration of Au-NPs and the Au-NPs agglomerate in the following order: 5-UMP $>$ 5-GMP $>$ 5-CMP > 5-AMP. The chemical structures of the nucleotides (Scheme 3) indicate that each moiety has an anionic phosphate group and several neutral $\mathrm{N}$ - and O-coordinating sites. The effective charge of these nucleotides is in the order 5-UMP $(-1.002)>5$-GMP $(-0.835) \gg 5$-AMP $(-0.130)>5$-CMP $(-0.038)$ [34]. The Au-NPs are surrounded by the highly positively charged 28-MCPAC. Thus, there are two possible interactions that could lead to the agglomeration of nanoparticles: (i) interactions of macrocyclic polyammonium cations with the negative end of the nucleotides could leave the bare nanoparticles susceptible to the agglomeration; (ii) binding of nanoparticles by nucleotides could lead to the agglomeration. Previous reports demonstrate that the binding of nucleosides through their purine and pyrimidines bases to Au-NPs leads to particle agglomeration accompanied by a plasmon frequency red-shift $[46,47]$. In another report [48], the prepared Au-NPs in the presence of triphosphorylated adenosine (ATP) are stable whereas in the presence of monophosphorylated adenosine (AMP), particles aggregate. Furthermore, the binding affinity of DNA bases is ranked in the order of adenosine $>$ cytosine $>$ guanine $>$ thymidine (methyluridine) [46-48]. Adenosine binds strongly to the gold surface and provides comparatively better stability and a lower rate of agglomeration compared to either cytosine or guanine. On the other hand, the interaction of thymidine with the gold surface is considerably lower and consequently much less or no agglomeration occurs. Jang [47] demonstrated the binding mode of nucleosides with nanoparticles. According to this report [47], adenosine binds the gold surface via imidazole- $\mathrm{N}$ and $-\mathrm{NH}_{2}$ group (in a bidentate fashion), cytosine binds via pyrimidine-N,O (in a bidentate fashion), guanine binds via purine- $\mathrm{N}, \mathrm{O}$ (in a bidentate fashion), and thymidine binds via the oxygen of the pyrimidine ring in a monodentate fashion. Our results demonstrate that the nucleotides show different trends to- 

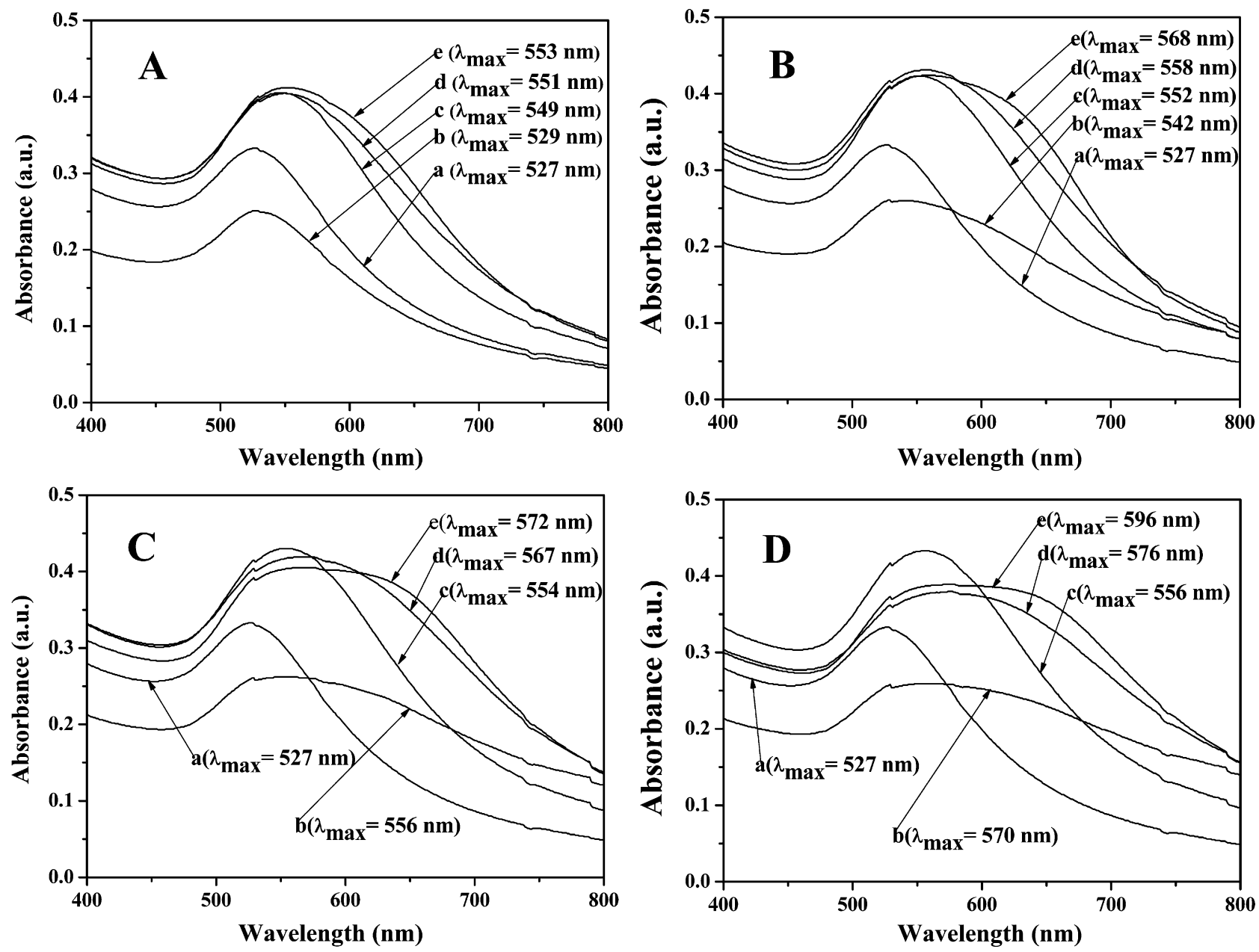

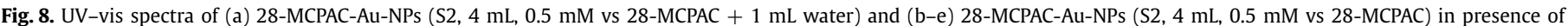

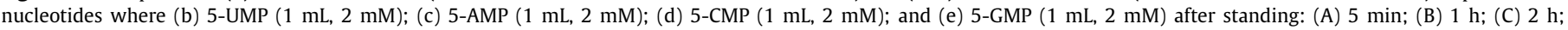
and (D) $4 \mathrm{~h}$.

ward binding of the highly positively charged 28-MCPAC-capped Au-NPs, but do not contradict previously reported results. In our study, binding affinity of nucleotides and their effective charge are to be considered. 5-AMP and 5-CMP carry negligible negative charge; they would interact with 28-MCPAC-capped Au-NPs through coordination, replacing the surface species in the order of 5-AMP > 5-CMP. 5-GMP carries a comparatively high negative charge, and its coordinating ability is comparable with that of 5-CMP. Therefore, from the UV-vis spectrum we suggest that 5GMP first binds the Au-NPs like 5-AMP and 5-CMP, but due to the high negative charge, 5-GMP then interacts with the macrocyclic polyammonium cations too, leading to the agglomeration of AuNPs at a faster rate than those of 5-AMP and 5-CMP. However, 5-UMP has the least coordinating ability and in general cannot appreciably agglomerate Au-NPs [46-48]. Nevertheless, with 28MCPAC-Au-NPs it interacts strongly with the surface macrocyclic polyammonium cations and makes the particles bare and unmodified, leading to the agglomeration most effectively compared to that of other nucleotides do. This is due to the fact that 5-UMP carries greatest negative charge among the nucleotides. As a matter of fact, in the presence of 5-UMP, immediate precipitation of Au-NPs occurs and consequently, the decrease of intensity of the surface plasmon band is observed rather than spectral red-shifting (Fig. $8 \mathrm{~A}(\mathrm{a})$ ). The photographs of all solutions are shown in Fig. 9. The color change (Fig. 9) is also indicative, as the pink-red color of 28-MCPAC-capped Au-NPs becomes paler in the presence of 5-
UMP (b), whereas it changes to bluish-pink in 5-AMP (c), 5-CMP (d), and 5-GMP (e) within 5 min (Fig. 9A). After standing for $4 \mathrm{~h}$ (Fig. 9D), the red-pink color of Au-NPs changes to almost colorless for 5-UMP (b), blue for 5-CMP (d) and GMP (e), and bluish-pink for 5-AMP (c).

\section{Summary}

We have prepared stable, highly water dispersion underivatized Au-NPs. For the stabilization of nanoparticles, we employed a water-soluble macrocyclic polyammonium chloride (28-MCPAC), which is well-recognized anion receptor. Macrocyclic polyammonium chloride capping of particles serves a two-fold purpose, that of stabilization of particles and surface fictionalization (with its cations) of particles for sensing anions. Particles were spherical and well-separated. It has been demonstrated that the macrocycle molecules adsorbed on the Au-NPs might form ion-pairs with $\mathrm{Cl}^{-}$ions attached to the Au surfaces, and the cationic macrocycle surrounded the $\mathrm{Cl}^{-}$layer by electrostatic interactions. 28-MCPAC-AuNPs with different core diameters are obtained by tuning the 28-MCPAC: $\mathrm{HAuCl}_{4}$ ratio. The potentiality of the assynthesized particles for sensing nucleotides, 5-AMP, 5-CMP, 5GMP, and 5-UMP were investigated spectroscopically. Nucleotideassisted agglomerations of 28-MCPAC-Au-NPs follow the order: 5-UMP $>$ 5-GMP $>$ 5-CMP $>$ 5-AMP. The macrocyclic polyammonium chloride-stabilized water dispersible Au-NPs can have the 

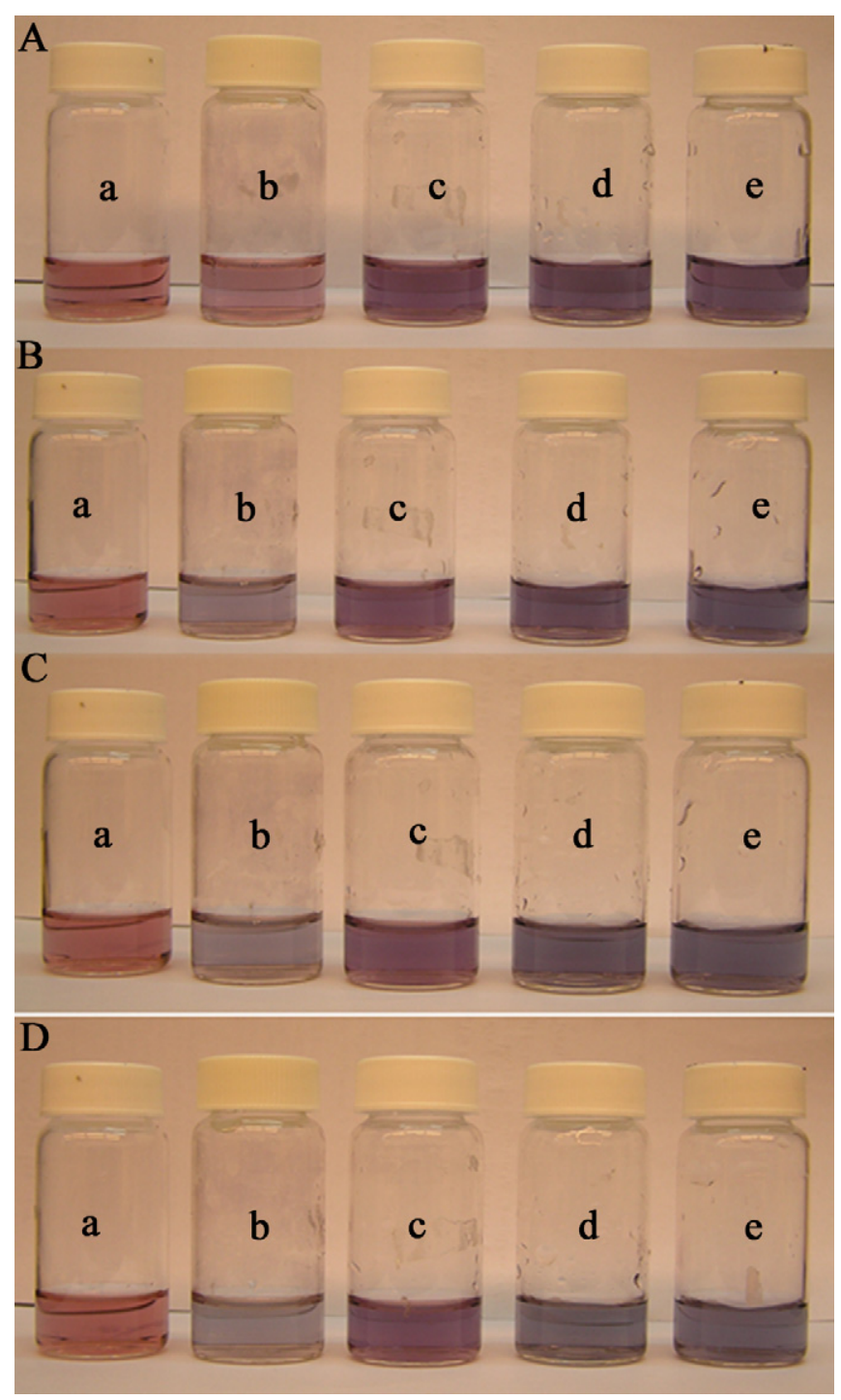

Fig. 9. Photographs of (a) 28-MCPAC-Au-NPs (S2, $4 \mathrm{~mL}, 0.5 \mathrm{mM}$ vs 28-MCPAC + $1 \mathrm{~mL}$ water) and (b-e) 28-MCPAC-Au-NPs (S2, $4 \mathrm{~mL}, 0.5 \mathrm{mM}$ vs 28-MCPAC) in presence of nucleotides where (b) 5-UMP ( $1 \mathrm{~mL}, 2 \mathrm{mM})$; (c) 5-AMP $(1 \mathrm{~mL}, 2 \mathrm{mM})$; (d) 5-CMP (1 mL, $2 \mathrm{mM})$; and (e) 5-GMP (1 mL, $2 \mathrm{mM}$ ) after standing: (A) $5 \mathrm{~min}$; (B) $1 \mathrm{~h}$; (C) $2 \mathrm{~h}$; and (D) $4 \mathrm{~h}$.

potential use in biosensing and biolabeling applications. Au-NPs in water at $\mathrm{pH} 4.55$ were prepared without any stabilizer. Particles without stabilizer were short lived and TEM image showed that they aggregate following a quasi-two-dimensional self-assembly array. It could be important materials in nanodevices.

\section{Acknowledgments}

The authors are thankful to the National Science Council of Taiwan for financial support (Grant Nos. NSC 95-2113-M-002-002 and NSC 95-2113-M-002-023-MY3).

\section{References}

[1] J.H. Fendler, Nanoparticles and Nanostructured Films, VCH, Weinheim, Germany, 1998.

[2] K.J. Klabunde, Nanoscale Materials in Chemistry, VCH, Weinheim, Germany, 2001.

[3] C.M. Goodman, C.D. McCusker, T. Yilmaz, V.M. Rotello, Bioconjugate Chem. 15 (2004) 897.

[4] L.R. Hirsch, R.J. Stafford, J.A. Bankson, S.R. Shersen, B. Rivera, R.E. Price, J.D. Hazle, N.J. Halas, J.L. West, Proc. Natl. Acad. Sci. USA 100 (2003) 13549.

[5] J.F. Hainfeld, D.N. Slatkin, H.M. Smilowitz, Phys. Med. Biol. 49 (2004) N309.

[6] M. Thomas, A. Klibanov, Proc. Natl. Acad. Sci. USA 100 (2003) 9138.

[7] X. Huang, I.H. El-Sayed, X. Yi, M.A. El-Sayed, J. Photochem. Photobiol. B: Biol. 81 (2005) 76.

[8] R. Elghanian, J.J. Storhoff, R.C. Mucic, R.L. Letsinger, C.A. Mirkin, Science 277 (1997) 1078.

[9] R. Wilson, Chem. Commun. (2003) 108.

[10] D.C. Hone, A.H. Haines, D.A. Russell, Langmuir 19 (2003) 714.

[11] B. Nolting, J.J. Yu, G.Y. Liu, S.J. Cho, S. Kauzlarch, J. Gervay-Hague, Langmuir 19 (2003) 6465.

[12] S. Watanabe, M. Sonobe, M. Arai, Y. Tazume, T. Matsuo, T. Nakamura, K. Yoshida, Chem. Commun. (2002) 2866.

[13] S.Y. Lin, S.W. Liu, C.M. Lin, C.H. Chen, Anal. Chem. 74 (2002) 330.

[14] S.O. Obare, R.E. Hollowell, Langmuir 18 (2002) 10407.

[15] Y. Kim, R.C. Johnson, J.T. Hupp, Nano Lett. 1 (2001) 165.

[16] M. Brust, M. Walker, D. Bethell, D.J. Schiffrin, R. Whyman, J. Chem. Soc. Chem. Commun. (1994) 801

[17] M.J. Hostetler, S.J. Green, J.J. Stokes, R.W. Murray, J. Am. Chem. Soc. 118 (1996) 4212.

[18] M. Brust, J. Fink, D. Bethell, D.J. Schiffrin, C. Kiely, J. Chem. Soc., Chem. Commun. (1995) 1655.

[19] A. Badia, L. Demers, L. Dickinson, F.G. Morin, R.B. Lennox, L. Reven, J. Am. Chem. Soc. 119 (1997) 11104.

[20] J.G. Worden, A.W. Schaffer, Q. Huo, Chem. Commun. (2004) 518.

[21] A.C. Templeton, M.J. Hostetler, C.T. Kraft, R.W. Murray, J. Am. Chem. Soc. 120 (1998) 1906.

[22] J. Fink, C.J. Kiely, D. Bethell, D.J. Schiffrin, Chem. Mater. 10 (1998) 922.

[23] W. Chen, S. Dong, E. Wang, Langmuir 19 (2003) 9434.

[24] A.C. Templeton, S. Chen, S.M. Gross, R.W. Murray, Langmuir 15 (1999) 66.

[25] S. Chen, Langmuir 15 (1999) 7551.

[26] S. Chen, K. Kimura, Langmuir 15 (1999) 1075.

[27] D.E. Cliffel, F.P. Zamborini, S.M. Gross, R.W. Murray, Langmuir 16 (2000) 9699

[28] A.C. Templeton, D.E. Cliffel, R.W. Murray, J. Am. Chem. Soc. 121 (1999) 7081.

[29] J. Turkevich, G. Garton, P.C. Stevenson, J. Colloid Sci. 9 (1954) 26.

[30] G. Frens, Nature 241 (1973) 20.

[31] E. Garcia-Espana, P. Diaz, J.M. Llinares, A. Bianchi, Coord. Chem. Rev. 250 (2006) 2952.

[32] C.Y. Liu, W.H. Chen, J. Chromatogr. A 815 (1998) 251.

[33] C.Y. Liu, T.H. Chen, T.K. Misra, J. Chromatogr. A 1154 (2007) 407.

[34] S.Y. Lin, C.Y. Liu, Electrophoresis 24 (2003) 2973.

[35] W.H. Chen, C.C. Lin, T.S. Chen, T.K. Misra, C.Y. Liu, Electrophoresis 24 (2003) 970.

[36] S.Y. Lin, G.R. Wang, Q.P. Huang, C.Y. Liu, Electrophoresis 27 (2006) 4257.

[37] A. Buryak, A. Pozdnoukhov, K. Severin, Chem. Commun. (2007) 2366.

[38] K. Torigoe, K. Esumi, J. Phys. Chem. B 103 (1999) 2862.

[39] J.A. Creighton, D.G. Eadon, J. Chem. Soc. Faraday Trans. 87 (1991) 388.

[40] M. Kerker, The Scattering of Light and Other Electromagnetic Radiation, Academic Press, New York, 1969, p. 38.

[41] S. Lin, M. Li, E. Dujardin, C. Girard, S. Mann, Adv. Mater. 17 (2005) 2553.

[42] K.H. Su, Q.H. Wei, X. Zhang, J.J. Mock, D.R. Smith, S. Schultz, Nano Lett. 3 (2003) 1087.

[43] C.C. Chen, C.H. Hsu, P.L. Kuo, Langmuir 23 (2007) 6801.

[44] S.T. Wang, J. Yan, L. Chen, Mater. Lett. 59 (2005) 1383.

[45] M.C. Daniel, D. Astruc, Chem. Rev. 104 (2004) 293.

[46] J.J. Storhoff, R. Elghanian, C.A. Mirkin, R.L. Letsinger, Langmuir 18 (2002) 6666.

[47] N.H. Jang, Bull. Korean Chem. Soc. 23 (2002) 1790.

[48] W. Zhao, F. Gonzaga, Y. Li, M.A. Brook, Adv. Mater. 19 (2007) 1766. 